\title{
To Study The Clinical Profile And Complications And Response To Treatment of Patients With Malaria At Tertiary Care Center of North India
}

\author{
Sood $\mathrm{R}^{1}$, Timothy $\mathrm{R}^{1}$, Singh $\mathrm{N}^{2}$, Mani $\mathrm{A}^{2}$, Das $\mathrm{S}^{3}$, Mahajan $\mathrm{A}^{4}$ \\ ${ }^{I}$ Dr.Rahul Sood, Department Of Nephrology, Christian Medical College And Hospital, Ludhiana, Punjab, India. \\ ${ }^{I}$ Dr.Timothy Rajamanickam, Department Of Nephrology, Christian Medical College And Hospital, Ludhiana, \\ Punjab, India. \\ ${ }^{2}$ Dr.Navjot Singh, Department Of Medicine, Christian Medical College And Hospital, Ludhiana, Punjab, India. \\ ${ }^{2}$ Dr.Anna Mani, Department Of Medicine, Christian Medical College And Hospital, Ludhiana, Punjab, India. \\ ${ }^{3}$ Dr.Shiela Das, Department Of Pathology, Christian Medical College And Hospital, Ludhiana, Punjab, India. \\ ${ }^{4}$ Dr.Amit Mahajan, Department Of Surgery, Christian Medical College And Hospital, Ludhiana, Punjab, India.
}

\begin{abstract}
The aim of the study is to describe the clinical manifestations, complications and response to treatment of patients with Malaria, and to find out the factors which determine the severity of the disease. This will be a one year retrospective and one and half year prospective study. All patients diagnosed to have Malaria will be included in this study. Clinical features, complications and response to treatment will be recorded carefully and the data will be analysed by the appropriate statistical methods.
\end{abstract}

Keywords: Clinical profile, complications, response, factors, malaria

\section{Introduction}

India contributes to about $70 \%$ of Malaria in the South East Asia region. Annually India reports about two million cases and 1,000 deaths attributable to Malaria [1]. There exists heterogeneity and variability in the transmission between and within the states of the country as many ecotypes / paradigms of Malaria have been recognized. The high burden populations are ethnic tribes living in forested pockets of states like Orissa, Jharkhand, Madhya Pradesh, Chhattisgarh and the North Eastern states which contribute to the bulk of morbidity and mortality due to Malaria in the country.

Among the four species of Plasmodium, Plasmodium falciparum and vivax are commonly found in our country. Disease caused by Plasmodium vivax Malaria used to be called benign tertian. Malaria as it had an uncomplicated course and responded quickly to chloroquine. In contrast Plasmodium falciparum causes severe Malaria and often produces multiorgan failure unless treated early with multiple drugs. Recently there have been some isolated reports showing severe Plasmodium vivax Malaria associated with thrombocytopenia, cerebral malaria, acute respiratory distress syndrome, acute renal failure and hepatic dysfunction. Kochar et al in a study reported several cases of vivax Malaria with multiorgan dysfunction syndrome where mixed infection was ruled out using PCR testing [2] . Profound thrombocytopenia is a well recognized complications of falciparum malaria but recently there have been several reports of vivax malaria with thrombocytopenia [3-4] . Direct lytic effect, immunological reactions, splenic sequestration and oxidative stress are some of suggested mechanisms for thrombocytopenia [5-6]. Acute respiratory distress syndrome (ARDS), hepatic involvement and renal involvement are common in Plasmodium falciparum Malaria; these complications also have been reported in Plasmodium vivax Malaria [7-12]. Small airway obstruction, gas exchange alteration increased phagocytic activity and accumulation of pulmonary monocytes is suggestive mechanisms for ARDS in Malaria [13].

Morbidity and mortality of Plasmodium vivax have increased recently due to the serious complications associated with it. There are very few prospective studies on clinical profile of Vivax Malaria. This study is being undertaken to document the changing clinical profile of this common disease.

\section{Aims and Objectives}

To describe the clinical manifestations, complications and response to treatment of patients with Malaria.

\section{Material and Methods}

This was a descriptive study, which was done in the Department of Medicine, Christian Medical College and Hospital, Ludhiana, over a period of two and half years (one and a half year prospective and one year retrospective study). In retrospective study, data was collected from case records of all cases admitted to Christian Medical College and Hospital, Ludhiana, with diagnosis of Malaria from $1^{\text {st }}$ October 2008 to $30^{\text {th }}$ 
September, 2009. In prospective study ( $1^{\text {st }}$ October 2009 to $31^{\text {st }}$ March, 2011), all patients admitted and diagnosed as Malaria were included.

Diagnosis of Malaria was made by examining the peripheral blood smear (thick and thin smear). Parasite index will be calculated in all cases. An additional test namely OptiMAL test was done to rule out mixed infection.

OptiMAL is a rapid (10 minutes) malaria detection test which utilizes a dipstick coated with monoclonal antibodies against the intracellular metabolic enzyme parasite lactate dehydrogenase. Differentiation of malaria parasite was based on antigenic difference between $\mathrm{pLDH}$ isoforms. OptiMAL has sensitivity of $95.3 \%$ and specificity of $100 \%$ for Plasmodium falciparum and sensitivity of $96 \%$ and specificity of $100 \%$ for Plasmodium vivax.

Complete blood count, renal function test, liver function test, arterial blood gases analysis, chest x-ray will be done. Imaging (CT scan, MRI) wherever required. Treatment was given to all patients as per WHO guidelines. Patient's clinical features, complications, response to treatment was recorded as per data collection sheet. Patients were categorized into Plasmodium vivax, Malaria, Plasmodium falciparum Malaria and mixed infection.

\section{Statistical analysis}

To compare mean values of a variable between more than two groups, we used analysis of variance [ANOVA] and to compare two proportions of subjects we applied Z-test.

\section{Results}

This was a descriptive study, done in the Department of Medicine, Christian Medical College and Hospital, Ludhiana, study was done over a period of 21/2 years (one year retrospective from 1st October, 2008 to 30th September, 2009 and one and half year prospective from 1st October, 2009 to 31st March, 2011). All patients admitted at Christian Medical College and Hospital, Ludhiana with diagnosis of Malaria were included and following observations were made. . A total of 124 patients were studied 92 patients of Plasmodium vivax, 21 patients of Plasmodium falciparum and 11 patients of Mixed malaria. Mean age of Plasmodium vivax 34.66 +15.91 , Plasmodium falciparum $37.9+13.8$ and Mixed malaria $32.82+10.1$ years. Male : Female ratio was 3.8 :1. Headache and cough were seen significantly more in Plasmodium vivax where as diarrhea and altered sensorium were more seen in Plasmodium falciparum and Mixed cases. Most common signs were pallor, jaundice and hepatosplenomegaly. Pallor and jaundice were seen significantly more in Plasmodium falciparum and Mixed malaria. 49/124 patients had haemoglobin $<10 \mathrm{gm} / \mathrm{dl}$ and 119/124 (95.92\%) had thrombocytopenia. Complications observed were severe anaemia $<7 \mathrm{gm} / \mathrm{dl}$ in 10 patients, Hypotension in 23 patients, renal dysfunction (creat $>1.2 \mathrm{mg} / \mathrm{dl}$ ) in 33 patients, raised bilirubin $>3 \mathrm{mg} \%$ in 26 patients, metabolic acidosis in 9 patients, ARDS in 13 patients and encephalopathy in 17 patients. Hypotension and encephalopathy were found significantly more in Plasmodium falciparum and Mixed malaria. Severe malaria was observed in 39/124 patients of which $25(27.12 \%)$ were of Plasmodium vivax, $9(42.86 \%)$ were of Plasmodium falciparum and 5 $(45.45 \%)$ were of Mixed malaria. Thrombocytopenia and jaundice were the most frequent complications in the severe cases. Mixed malaria was found in 11 cases. 5 of them were severe cases. 54/92 of plasmodium vivax cases responded to chloroquine alone. 31 patients (33.7\%) required artesunate or combinations. 10/124 patients $(8.06 \%)$ expired. Out of these $4(4.38 \%)$ were of plasmodium vivax, 3 (14.28\%) were plasmodium falciparum and $3(27.27 \%)$ were mixed malaria. $8 / 10$ patients who expired had four or more organ dysfunction.

ARDS had the most significant correlation with mortality. Other significant factors contributing to death were hypotension, encephalopathy, jaundice, severe anemia and renal failure. Age and platelet counts had no significant correlation to mortality.

Table 1

Distribution Of Subjects According To OPTIMAL And MP Smear Test Results

\begin{tabular}{|l|c|c|c|c|}
\hline Results & OptiMAL test & Percentage & $\begin{array}{l}\text { MP Smear } \\
\text { Positive }\end{array}$ & Percentage \\
\hline PV positive & 92 & 74.19 & $74(88)$ & 62.7 \\
\hline PF positive & 21 & 16.94 & $10(19)$ & 8.47 \\
\hline Mixed malaria & 11 & 8.87 & $7(11)$ & 7.63 \\
\hline Total & 124 & 100.00 & $91(118)$ & 77.1 \\
\hline
\end{tabular}

Table 1 shows the distribution of subjects according to optiMAL test and MP smear reports

Table 2 Age distribution of subjects 
To Study The Clinical Profile And Complications And Response To Treatment Of Patients...

\begin{tabular}{|l|l|l|l|l|l|l|}
\hline \multirow{2}{*}{ Age( years) } & \multicolumn{2}{|c|}{ PF Positive } & \multicolumn{2}{c|}{ PV Positive } & \multicolumn{2}{c|}{ Mixed } \\
\cline { 2 - 7 } & No. & Percentage & No. & Percentage & No. & Percentage \\
\hline $11-20$ & 2 & 9.52 & 23 & 25.00 & 2 & 18.18 \\
\hline $21-30$ & 4 & 19.05 & 23 & 25.00 & 4 & 36.36 \\
\hline $31-40$ & 9 & 42.86 & 21 & 22.83 & 2 & 18.18 \\
\hline $41-50$ & 1 & 4.76 & 8 & 8.69 & 0 & 0.00 \\
\hline $51-60$ & 3 & 14.29 & 8 & 8.69 & 1 & 9.09 \\
\hline$>60$ & 2 & 9 & 9.78 & 2 & 18.18 \\
\hline Mean + SD & 9.52 & \multicolumn{2}{|c|}{$34.66+15.91$} & & $32.82+10.1$ \\
\hline
\end{tabular}

P value: 0.153

Table 2 demonstrates the age distribution of the subjects. Majority (> 70\%) of the cases were below 40 years of age. There were very few number of cases above 60 years of age. The youngest and oldest patient in this study were of 13 and 75 years of age respectively.

Table 3 Clinical Features Of Malaria

\begin{tabular}{|c|c|c|c|c|c|c|c|}
\hline \multirow{2}{*}{$\begin{array}{l}\text { Constitutional } \\
\text { symptoms }\end{array}$} & \multicolumn{2}{|c|}{ PF Positive } & \multicolumn{2}{|c|}{ PV Positive } & \multicolumn{2}{|c|}{ Mixed } & \multirow[t]{2}{*}{$\mathrm{P}$ value } \\
\hline & No. & Percentage & No. & Percentage & No. & Percentage & \\
\hline Fever & & & & & & & 0.104 \\
\hline Intermittent & 21 & 100.00 & 82 & 89.13 & 11 & 100.00 & \\
\hline Continuous & 0 & 0.00 & 10 & 10.87 & 0 & 0.00 & \\
\hline Headache & 4 & 19.05 & 43 & 46.74 & 4 & 36.36 & 0.042 \\
\hline Vomiting & 9 & 42.86 & 39 & 42.39 & 4 & 36.36 & 0.464 \\
\hline Abdominal pain & 7 & 33.33 & 23 & 25.00 & 0 & 0.00 & 0.045 \\
\hline Diarrhea & 6 & 28.57 & 8 & 8.69 & 3 & 27.27 & 0.039 \\
\hline Cough & 1 & 0.05 & 21 & 22.83 & 2 & 18.18 & 0.052 \\
\hline Breathing difficulty & 4 & 19.05 & 10 & 10.87 & 0 & 0.00 & 0.107 \\
\hline Altered sensorium & 5 & 23.81 & 6 & 6.52 & 6 & 54.55 & 0.00128 \\
\hline $\begin{array}{l}\text { Bleeding from any } \\
\text { site }\end{array}$ & 3 & 14.29 & 13 & 14.13 & 0 & 0.00 & 0.1253 \\
\hline Swelling of feet & 1 & 4.76 & 1 & 1.08 & 0 & 0.00 & 0.22439 \\
\hline Seizures & 0 & 0.00 & 1 & 1.08 & 1 & 9.09 & 0.11754 \\
\hline \multicolumn{7}{|l|}{ Duration of fever } & \\
\hline Upto 10 days & 17 & 80.95 & 86 & 93.48 & 11 & 100.00 & \\
\hline $11-20$ days & 2 & 9.52 & 5 & 5.43 & 0 & 0.00 & \\
\hline$>20$ days & 2 & 9.52 & 1 & 1.09 & 0 & 0.00 & \\
\hline Mean + SD & \multicolumn{2}{|c|}{$11.24+18.64$} & \multicolumn{2}{|c|}{$5.91+3.49$} & \multicolumn{2}{|c|}{$4.36+2.11$} & \\
\hline
\end{tabular}

P value: 0.136

Table 3 shows the clinical features of the cases. Fever was intermittent in $91.94 \%$ of the cases, continuous in $8.06 \%$ of the cases

Table 4: Signs

\begin{tabular}{|c|c|c|c|c|c|c|c|}
\hline \multirow[t]{2}{*}{ Sign } & \multicolumn{2}{|c|}{ PF Positive } & \multicolumn{2}{|c|}{ PV Positive } & \multicolumn{2}{|c|}{ Mixed } & \multirow[t]{2}{*}{$\mathrm{p}$ value } \\
\hline & No. & Percentage & No. & Percentage & No. & Percentage & \\
\hline Pallor & 15 & 71.43 & 50 & 54.34 & 9 & 81.82 & 0.25595 \\
\hline Jaundice & 9 & 42.86 & 21 & 22.83 & 4 & 36.36 & 0.46449 \\
\hline $\begin{array}{l}\text { Hypotension } \\
\text { (SBP <90mmh) }\end{array}$ & 2 & 9.52 & 16 & 17.39 & 5 & 45.45 & 0.04197 \\
\hline Edema feet & 4 & 19.05 & 1 & 1.08 & 1 & 9.09 & 0.00166 \\
\hline Puffiness of face & 0 & 0.00 & 2 & 2.17 & 1 & 9.09 & 0.24203 \\
\hline Petechie/ecchymosis & 0 & 0.00 & 3 & 3.26 & 2 & 18.18 & 0.04856 \\
\hline Abdominal distension & 5 & 23.81 & 8 & 8.69 & 2 & 18.18 & 0.05004 \\
\hline Abdominal tenderness & 4 & 19.05 & 12 & 13.04 & 0 & 0.00 & 0.10663 \\
\hline Hepatomegaly & 13 & 61.90 & 40 & 43.48 & 3 & 27.27 & 0.05266 \\
\hline Splenomegaly & 9 & 42.86 & 41 & 44.56 & 4 & 36.36 & 0.46449 \\
\hline Ascites & 0 & 0.00 & 2 & 2.17 & 0 & 0.00 & 0.24203 \\
\hline \multicolumn{8}{|l|}{ Level of consciousness } \\
\hline Drowsy & 2 & 9.52 & 3 & 3.26 & 2 & 18.18 & 0.13103 \\
\hline Stuporous & 3 & 14.29 & 3 & 3.26 & 4 & 36.36 & 0.00146 \\
\hline Coma & 0 & 0.00 & 0 & 0.00 & 0 & 0.00 & \\
\hline
\end{tabular}

Table 4 shows signs on clinical examination of the cases. Pallor, jaundice and hepatosplenomegaly were the most common signs observed. Pallor and jaundice were seen significantly more in falciparum and mixed malaria. Hypotension was noted in 23 (18.55\%) patients. Pedal edema was present in 6 patients of which 
5 was cases of falciparum malaria. There were 17 cases of alteration of sensorium out of which 6 were cases of mixed malaria.

Table 5: Showing complications of malaria

\begin{tabular}{|c|c|c|c|c|c|c|c|}
\hline \multirow[t]{2}{*}{ Complications } & \multicolumn{2}{|c|}{ PF Positive } & \multicolumn{2}{|c|}{ PV Positive } & \multicolumn{2}{|c|}{ Mixed } & \multirow[t]{2}{*}{$\mathrm{p}$ value } \\
\hline & No. & Percentage & No. & Percentage & No. & Percentage & \\
\hline $\begin{array}{l}\text { Severe anemia } \\
(\mathrm{Hb}<7 \mathrm{gm} \%)\end{array}$ & 4 & 19.05 & 6 & 6.52 & 0 & 0.00 & 0.10663 \\
\hline Hypotension & 2 & 9.52 & 16 & 17.39 & 5 & 45.45 & 0.04197 \\
\hline $\begin{array}{l}\text { Hypoglycemia } \\
\text { RBS }<60 \mathrm{mg} \%\end{array}$ & 0 & 0.00 & 1 & 1.09 & 1 & 9.09 & 0.11754 \\
\hline Renal failure(crt>1.2) & 7 & 33.33 & 20 & 21.74 & 6 & 54.54 & 0.0414 \\
\hline Deranged LFT & & & & & & & \\
\hline Raised Bilirubin $>1.1$ & $14(17)^{*}$ & 82.35 & $37(56)$ & 66.07 & $6(8)$ & 75.00 & 0.12877 \\
\hline Raised SGOT & 13 & 61.90 & $33(82)$ & 40.24 & $6(9)$ & 66.67 & 0.10852 \\
\hline Raised SGPT & 13 & 61.90 & $29(82)$ & 35.36 & $3(9)$ & 33.33 & 0.11478 \\
\hline Metabolic Acidosis & $5(10)^{*}$ & & $3(20)$ & & $1(5)$ & & 0.21301 \\
\hline ARDS/ALI/ Hypoxia & 4 & 19.04 & 7 & 7.60 & 2 & 18.18 & 0.14059 \\
\hline Encephalopathy & 5 & 23.81 & 6 & 6.52 & 6 & 54.54 & 0.00128 \\
\hline
\end{tabular}

*figures in the brackets stand for the number of patients in which the test was performed.

Table 5, showed the complications of malaria. Hb was less than $7 \mathrm{gm} \%$ in 11 patients, out of them four had $\mathrm{Hb}$ less than $5 \mathrm{gm} \%$. Hypotension was noted in 21 patients at the time of admission. There were 2 patients who developed hypotension during hospitalization. There were statistically more no. of patients with complication of renal dysfunction and encephalopathy in P.falciparum and mixed malaria group. ARDS/ ALI /Hypoxia was defined as $\mathrm{PaO} 2 / \mathrm{FIO} 2<200 \mathrm{~mm} \mathrm{Hg}$ along with radiological appearance of bilateral non homogenous opacities and respiratory distress. Thirteen patients had ARDS/ ALI /Hypoxia in our study. Nine patients had metabolic acidosis.

Table 6 : Frequency of various criteria for severity in Severe malaria

\begin{tabular}{|c|c|c|c|c|}
\hline Criteria & $\begin{array}{c}\text { P. vivax } \\
\text { No(\%) of patients } \\
25(27.1) \\
\end{array}$ & $\begin{array}{c}\text { P. falciparum } \\
\mathrm{No}(\%) \text { of patients } \\
9(42.86)\end{array}$ & $\begin{array}{c}\text { Mixed } \\
\mathrm{No}(\%) \text { of patients } \\
5(45.45)\end{array}$ & $\begin{array}{l}\text { TotalNo(\%) of } \\
\text { patients } \\
39(31.45) \\
\end{array}$ \\
\hline $\begin{array}{l}\text { Severe anemia } \\
<7 \mathrm{mg} \%\end{array}$ & 5 & 4 & 2 & 11 \\
\hline Encephalopathy & 3 & 3 & 4 & 10 \\
\hline Hypotension & 10 & 2 & 3 & 15 \\
\hline Jaundice > $3 \mathrm{mg} \%$ & 16 & 7 & 4 & 27 \\
\hline $\begin{array}{l}\text { Creatinine } \\
>3 \mathrm{mg} \%\end{array}$ & 3 & 3 & 0 & 6 \\
\hline $\begin{array}{l}\text { Thrombocytopenia < } \\
80,000\end{array}$ & 23 & 9 & 5 & 37 \\
\hline ARDS & 7 & 4 & 2 & 13 \\
\hline Hypoglycemia & 1 & 0 & 0 & 1 \\
\hline Acidosis & 3 & 4 & 1 & 8 \\
\hline Expired & 4 & 3 & 3 & 10 \\
\hline Upto 2 organ failure & 15 & 2 & 1 & 18 \\
\hline 3 or more organ failure & 10 & 7 & 4 & 21 \\
\hline
\end{tabular}

Table 6 shows the frequency of various criteria for severity in cases of severe malaria. The most common complications observed were thrombocytopenia followed by jaundice, MODS (> 3 organ dysfunction), hypotension and ARDS.

Table 7: Data of Patients with Mixed Malaria

\begin{tabular}{|l|l|l|l|l|l|l|l|l|l|l|l|}
\hline S.No & Age & Sex & BP & CNS & PO2 & Hb & Plts & Bilirubin & Creat & Outcome & $\begin{array}{l}\text { Duration of delay } \\
\text { in hospitilisation }\end{array}$ \\
\hline 1 & 60 & $\mathrm{~F}$ & $100 / 70$ & Conscious & 72 & 9.4 & 21,000 & - & 1.7 & Expired & 5 \\
\hline 2 & 35 & $\mathrm{M}$ & $90 / 60$ & Stuporous & $\begin{array}{l}250.9 \\
\text { Intubated }\end{array}$ & 8.9 & 14,000 & 10.7 & 2.0 & Expired & 3 \\
\hline 3 & 20 & $\mathrm{~F}$ & $90 / 70$ & Stuporous & $\begin{array}{l}353.1 \\
\text { intubated }\end{array}$ & 8.6 & 64,000 & 4.8 & 0.7 & Expired & 7 \\
\hline 4 & 25 & $\mathrm{M}$ & $120 / 80$ & Conscious & - & 10.6 & 71,000 & 1.99 & 0.9 & Improved & 4 \\
\hline 5 & 25 & $\mathrm{M}$ & $90 / 60$ & Stuporous & 54 & 10.1 & 37,000 & 6.1 & 2.0 & Improved & 3 \\
\hline 6 & 13 & $\mathrm{M}$ & $110 / 70$ & Conscious & - & 10.6 & 14,000 & - & 0.6 & Improved & 2 \\
\hline 7 & 25 & $\mathrm{M}$ & $90 / 60$ & Drowsy & 96 & 7.6 & 36,000 & 6.9 & 0.8 & Improved & 7 \\
\hline 8 & 65 & $\mathrm{M}$ & $110 / 70$ & Stuporous & - & 8.5 & $1,06,000$ & 0.5 & 0.5 & Improved & 8 \\
\hline
\end{tabular}


To Study The Clinical Profile And Complications And Response To Treatment Of Patients...

\begin{tabular}{|l|l|l|l|l|l|l|l|l|l|l|l|}
\hline 9 & 32 & $\mathrm{M}$ & $90 / 60$ & Conscious & - & 8.2 & 40,000 & 1.1 & 1.9 & Improved & 2 \\
\hline 10 & 36 & $\mathrm{M}$ & $110 / 70$ & Drowsy & - & 11.8 & 57,000 & - & 1.2 & Improved & 3 \\
\hline 11 & 25 & $\mathrm{M}$ & $110 / 80$ & Conscious & - & 9.2 & 29,000 & 2.2 & 1.4 & Improved & 4 \\
\hline
\end{tabular}

Table 7 shows the data of patients with mixed malaria. There were 11 cases of mixed infection, 5 out of these 11 cases fulfilled the criteria for severe malaria. Six of the patient had encephalopathy and 5 had hypotension, 6 had renal failure (creatinine $>1.2 \mathrm{mg} / \mathrm{dl}$ ) and 4 had bilirubin $>3 \mathrm{mg} \%$ and 2 had ARDS. Mortality was the highest in this group 3/11 (27.27\%).

Table 8: Treatment given for Malaria

\begin{tabular}{|l|c|c|c|}
\hline Treatment & PV & PF & Mixed \\
\hline Chloroquine only & 54 & - & - \\
\hline Chloroquine+Artesunate + Doxycycline & 14 & 13 & 6 \\
\hline Artesunate + chloroquine & 17 & 8 & 1 \\
\hline Chloroquine+ Doxycycline & 7 & - & - \\
\hline Artesunate+ Doxycycline + Quinine & - & - & 1 \\
\hline Chloroquine+Artesunate + Doxycycline + Quinine & - & - & 2 \\
\hline Artesunate + fansidar & - & - & 1 \\
\hline
\end{tabular}

Table 8 shows the treatment received by the patients. 54/92 of P.vivax malaria responded to chloroquine alone. Seven patients received Doxycycline in addition to Chloroquine. 31 patients received Artesunate and 14 of these received Doxycycline in addition. All cases of P. falciparum and mixed malaria were treated with Artesunate, Quinine and or Doxycycline. All patients of mixed malaria who were also given Chloroquine. Radical treatment with Primaquine was given to all patients of P. vivax and mixed malaria.

Table 9: Outcome

\begin{tabular}{|l|c|c|c|c|c|l|}
\hline \multirow{2}{*}{ Outcome } & \multicolumn{2}{|c|}{ PF Positive } & \multicolumn{2}{c|}{ PV Positive } & \multicolumn{2}{c|}{ Mixed } \\
\cline { 2 - 7 } & No. & Percentage & No. & Percentage & No. & Percentage \\
\hline Recovered & 18 & 85.71 & 88 & 95.65 & 8 & 72.72 \\
\hline Expired & 3 & 14.28 & 4 & 4.35 & 3 & 27.27 \\
\hline
\end{tabular}

Table 15 shows the outcome of the patients. In our study out of total 124 patients, $10(8.06 \%)$ patients died. Majority of the patients who expired had ARDS, thrombocytopenia, renal dysfunction and encephalopathy leading to MODS. The mortality was $9 / 92$ (4.35\%) for $\mathrm{P}$ vivax, $3 / 21$ (14.28\%) for $\mathrm{P}$ falciparum and $3 / 11$ $(27.27 \%)$ for mixed malaria.

\section{Discussion}

In our study, clinical and laboratory findings in malaria caused by various plasmodium species were being described. The prevalence of different types of malaria varies in different regions and states of India. In our study majority of the patients belonged to the state of Punjab where Plasmodium vivax is the predominant type of malaria. Higher prevalence in males is due to their occupations which bring them in contact with the mosquito vector. Fever was the leading clinical presentation. Fever was intermittent in $91.94 \%$ of the cases and continuous in $8.06 \%$ of the cases. In Plasmodium falciparum and mixed malaria, all cases had Intermittent type of fever, while in Plasmodium vivax $89.13 \%$ had intermittent and $10.87 \%$ had continuous type of fever. $86.29 \%$ of patients had chills and rigors. As in any other febrile illness, the fever was associated with generalized weakness and malaise in most of the patients. Headache and cough were seen significantly more in vivax malaria. Alteration in sensorium in malaria can be attributed to various factors namely: hyperpyrexia, lactic acidosis, hypoglycemia etc. The sequestration of parasites in the microvasculature of brain and other vital organs also leads to altered sensorium and generalized convulsions.

In our study, pallor, jaundice and hepatosplenomegaly were the most common signs observed. This high proportion of splenomegaly is in contrast to various international studies showing splenomegaly in $6.5 \%$ to $13 \%$ of the patients. [14-16]. Thrombocytopenia is a common feature of acute malaria and occurs in both P. falciparum and P.vivax regardless of the severity of infection. Severe thrombocytopenia has been reported most commonly with P. falciparum [17]. In our study, 95.24\% of falciparum, $95.65 \%$ of vivax and $100 \%$ cases of mixed malaria had thrombocytopenia. This hematological alteration is a common finding in malaria and a result of peripheral destruction and consumption. A few postulated mechanisms for thrombocytopenia in malaria include macrophage activation, increased levels of cytokines and antiplatelet immunoglobulin which cause platelet destruction. Anemia has frequently been associated with malaria. The two common causes of anemia are increased hemolysis and decreased rate of erythrocyte production from bone marrow. Malnutrition and intestinal parasitic infections aggravate this problem in highly endemic areas. Severe anemia is a common feature of P. falciparum malaria. In this study bleeding tendency was seen in 16 (12.90\%) patients, Severe 
hypotension associated with malaria also called algid malaria is characterized by circulatory collapse and extreme coldness of the body surface. Bacterial infections are common in case of severe malaria and include pneumonia especially in patients who are comatose, urinary tract infection, intravenous sepsis and spontaneous septicemia usually due to gram negative organism from GI tract. In the present study 23/124 patients had hypotension. Of these 16 were cases of $\mathrm{P}$. vivax malaria , 5/11 patients with mixed malaria also had hypotension. Renal involvement has been reported commonly with P. falciparum and occasionally with P.vivax infections. It can occur as an isolated complication or as a component of multiorgan involvement [18]. The precise mechanism of ARF in malaria is not clearly known. P. malariae is the established cause of chronic malarial nephropathy (quartan malarial nephropathy), although a few cases have been associated with P. vivax in children.

In our study, $33.3 \%$ of Plasmodium falciparum , 54.5\% of mixed malaria and $21.7 \%$ of Plasmodium vivax had renal dysfunction .Hepatic dysfunction in malaria is common, but hepatic encephalopathy is unusual, and most of the patients described have had either isolated infection with P. falciparum or a mixed infection with P.vivax [19] . In endemic areas, severe malaria should feature in the differential diagnosis of fulminant hepatic failure (FHF). It is important to differentiate the two since the prognosis in patients with severe hepatic injury due to malarial infection is better than FHF due to other causes. ARDS is considered to be the most severe form of acute lung injury in malaria and has been reported most commonly with P. falciparum malaria. Cerebral malaria is one of the most common and potentially life-threatening complications of P. falciparum malaria and is characterized by unarousable coma [20] . However, coma associated with P. vivax is rare, and its etiology is the least characterized of the syndromes associated with P.vivax. Complications in severe malaria are either sequestration related, such as cerebral malaria, renal dysfunction, hepatic dysfunction, and ARDS, or nonsequestration related, such as anemia and thrombocytopenia. Non-sequestration-related complications are known to occur in Plasmodium vivax infection quite frequently. However, for sequestration-related complications, it was always presumed that coexisting Plasmodium falciparum infection may evade appearance in blood film because of heavy sequestration.

\section{Conclusion}

Plasmodium vivax malaria was the commonest type of malaria observed. Severe plasmodium vivax was associated with all the complications described in falciparum malaria showing that it is no longer a benign disease. Chloroquine resistance was observed in 31/124 patients who needed treatment with Artesunate. Mixed malaria was associated with the largest proportion of severe malaria and the mortality was the highest in this group.

\section{References}

[1]. Dash AP, Valecha N, Anvikar AR and Kumar A. Malaria in India: Challenges and opportunities. J Biosc 2008; 33: 583-92.

[2]. Kochar DK, Saxena V, Singh N, Kumar SV, Das A. Plasmodium vivax malaria. Emerg Infect Dis 2005; 11: No.01/04-0519.

[3]. Makkar RP, Monga SM, Gupta AK. Plasmodium vivax malaria presenting with severe thrombocytopenia. Braz J Infect Dis 2002; 47: 24-6.

[4]. Rodriguez MAJ, Sanchez E, Varges M, Piccolo C, Colina R, Arria M. et al. Occurrence of thrombocytopenia in Plasmodium vivax Malaria. Clin Infect Dis 2005; 4: 130-1.

[5]. Fajarda LF, Tallent C. Malarial parasites within human platelets. JAMA 1974; 229: 1205.

[6]. Yamaguchi S, Kubota T, Yamaguchi T, Okamoto K, Izumi T, Takeda M. Severe thrombocytopenia suggesting immunological mechanisms in two cases of vivax malaria. Am J Hematol 1997; 56: 183-6.

[7]. Nautiyal A, Singh S, Parameswar G, Disalle M. Hepatic dysfunction in a patient of P. vivax Malaria. Med Gen Med 2005; 7: 8.

[8]. Kochar DK, Singh P, Aggarwal P, Kochar SK, Pokharna R, Sareen PK. Malarial hepatitis. J Assoc Phys India 2003; 51 : $1069-72$.

[9]. Anand AC, Ramji C, Narula AS, Singh W. Malarial hepatitis: a heterogeneous syndrome. Natl Med J India 1992; 5: 59-62.

[10]. Prakash J, Singh AK, Kumar NS, Saxena RK. Acute renal failure in Plasmodium vivax Malaria. J Assoc Phys India 2003; 51: 2657.

[11]. Maheswari A, Singh AK, Sinha DK, Tripathi K, Prakash J. Spectrum of renal diseases in Malaria. JAMA 2004; 102: 143-8.

[12]. Lomar AV, Vidal JE, Lomar FP, Barbas CV, Mato GJ, Boulos M. Acute respiratory distress syndrome due to vivax Malaria: case report and literature review. Braz J Infect Dis 2005; 9: 425-30.

[13]. Anstey NM, Jacups SP, Cain T, Pearson T, Zieseng PJ, Fisher DA. Pulmonary manifestations of uncomplicated falciparum and vivax Malaria: cough, small airway obstruction, impaired gas exchange and increased phagocytic activity. J Infect Dis 2002; 185: 1326-34.

[14]. Chandramohan D, Carneiro I, Kavishwar A, Brugha R, Desai V, Greenwood B. A clinical algorithm for the diagnosis of malaria: results of an evaluation in an area of low endemicity. Trop Med Int Health. 2001 jul; 6(7):505-10

[15]. Echeverri M, Tobón A, Alvarez G, Carmona J, Blair S. Clinical and laboratory findings of Plasmodium vivax malaria in Colombia, 2001. Rev Inst Med Trop Sao Paulo. 2003 Jan-Feb;45(1):29-34

[16]. Tangpukdee N, Thanachartwet V, Krudsood S, Luplertlop N, Pornpininworakij K, Chalermrut K, Phokham S, Kano S, Looareesuwan S, Wilairatana P. Minor liver profile dysfunctions in Plasmodium vivax, P. malaria and P. ovale patients and normalization after treatment. Korean J Parasitol. 2006 Dec;44(4):295-302

[17]. Aggarwal et al; 2005). Aggarwal A, Rath S, Shashiraj. Plasmodium vivax malaria presenting with severe thrombocytopenia. J Trop Pediatr. 2005 Apr;51(2):120-1

[18]. Das BS. Renal failure in malaria. J Vector Borne Dis. 2008 Jun;45(2):83-97

[19]. Bhalla A, Suri V, Singh V. Malarial hepatopathy. J Postgrad Med. 2006 Oct-Dec;52 (4):315-20.

[20]. Newton CR, Hien TT, White N. Cerebral malaria. J Neurol Neurosurg Psychiatry. 2000 Oct;69(4):433-41. 